\title{
Penis-Weltkarte
}

\section{Wer hat den Längsten?}

\author{
Kartenmaterial zu unterschiedlichen Themen finden sich zur Illustration eines Artikels in nahezu \\ jeder Zeitschrift: Darin werden Ölvorkommen, Bodenschätze, Einkommensverhältnisse und vieles mehr \\ den verschiedenen Ländern zugeordnet. Aber hätten Sie gewusst, dass auch die durchschnittliche \\ Penislänge kartografiert wurde?
}

W er sich (aus rein wissenschaftlichen Motiven natürlich) im Internet auf die Suche nach „Penislängen“ macht, riskiert, auf nicht ganz jugendfreien oder unseriösen Seiten zu landen. Doch es gibt auch Seiten mit sachlichem Anspruch, deren Inhalte weit über ein pubertäres Niveau hinausgehen. Unter www.targetmap.com/viewer.aspx? reportId $=3073$ findet der Urologe (und Laie) anschaulich aufbereitet und geografisch eingeordnet alles zu Penislänge und -umfang inklusive Standardabweichung und Verteilung der Häufigkeiten, Angaben zur Messmethode, aber auch zu Penisformen. Wer davon ausgeht, die verwendeten Daten seien an den Haaren herbeigezogen, sie vorgewarnt: Auch ein Autorenteam wie Schneider T, Sperling H, Lummen J, Syllwasschy J und Rübben $\mathrm{H}$ taucht mit einer Arbeit im umfangreichen Literaturverzeichnis auf. Darin finden sich auch weitere Urologen mit geläufigen Namen, viele der Daten stammen aus renommierten Publikationen wie Journal of Urology oder von Gesundheitsbehörden und werden regelmäßig aktualisiert. Die naheliegende Frage, ob sich die Größenverhältnisse laufend ändern, lässt sich nur spekulativ beantworten. Wie in URO-NEWS 6/2011 an dieser Stelle berichtet sind die meisten Versuche, die Penislänge zu vergrößern, nicht von Erfolg gekrönt. Von indischen SadhuMönchen ist bekannt, dass sie ihren Penis mit Gewichten beschweren, um ihn zu strecken. Dass sie damit ihre Erektionsfähigkeit einbüßen, dürfte den asketisch lebenden Sadhus egal sein, massentauglich dürfte die Methode damit aber nicht werden.

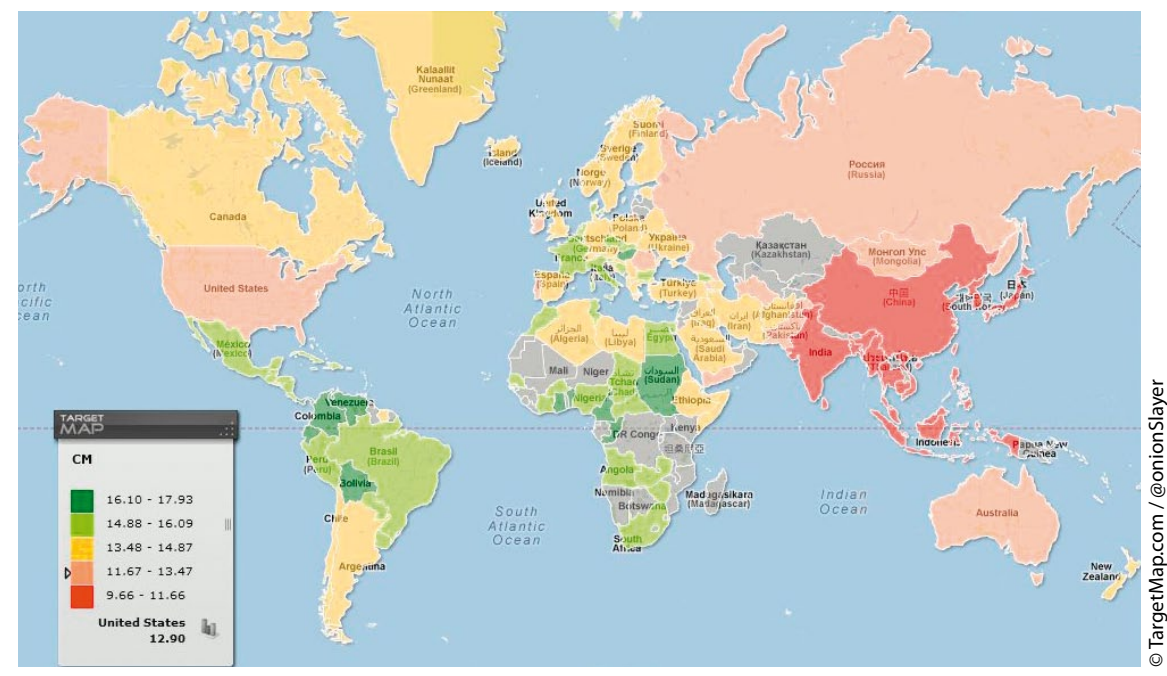

Penisgrößen weltweit

\section{Daten mit Skepsis zu begegnen}

Aber zurück zur Karte: Trotz der genannten, auf den ersten Blick verlässlichen Quellen fallen bei genauerem Hinsehen einige Merkwürdigkeiten auf: Obwohl die Vorfahren nahezu jeden US-Amerikaners entweder aus Europa, Afrika oder Lateinamerika stammen, ist die durchschnittliche US-amerikanische Länge gerade im Vergleich zu den Ahnen eher bescheiden. Ebenso implausibel erscheint, dass die Ungarn so viel größer abschneiden als ihre unmittelbaren Nachbarn aus Rumänien. Offensichtlich gibt es Diskrepanzen bei den jeweiligen Datenerhebungen. Aber vielleicht ist das auch besser so, denn wer weiß, wie zum Beispiel Deutschland im Vergleich zu anderen Ländern abschneiden würde, wenn es ein international einheitliches „Messprotokoll“" gäbe.
Was bringt die „Peniskarte"

Man kann natürlich nach der Bedeutung dieser Veröffentlichung fragen. Vielleicht ist sie für die Hersteller und Vertreiber von Kondomen interessant. Es wird ja kolportiert, die Japaner hätten hierzulande erhebliche Schwierigkeiten mit den europäischen Kondomgrößen. Der Autor, der die „penis map“ ins Netz gestellt hat, erläutert sein Vorgehen übrigens mit folgendem Bonmot, das fälschlicherweise dem brasilianischen Arzt Drauzio Varella zugeschrieben wurde: „Heutzutage wird fünfmal mehr in Medikamente für die männliche Potenz und Silikon für Frauen investiert als in die Alzheimer-Forschung. Daraus folgernd haben wir in ein paar Jahren alte Frauen mit großen Brüsten und alte Männer mit hartem Penis, aber keiner von denen kann sich daran erinnern, wozu das gut ist." Walther Grohmann, Sebastian Lux 